\title{
Climatological Characteristics of Daily Precipitation over Japan in the Kakushin Regional Climate Experiments Using a Non-Hydrostatic 5-km-Mesh Model: Comparison with an Outer Global 20-km-Mesh Atmospheric Climate Model
}

\author{
Sachie Kanada ${ }^{1}$, Masuo Nakano ${ }^{1}$, and Teruyuki Kato ${ }^{2}$ \\ ${ }^{1} J a p a n$ Agency for Marine-Earth Science and Technology, Yokohama, Japan \\ ${ }^{2}$ Japan Meteorological Agency, Tokyo, Japan
}

\begin{abstract}
The climatological characteristics of daily precipitation over Japan in the Kakushin regional climate change experiments using a non-hydrostatic model with a horizontal resolution of $5 \mathrm{~km}$ (NHM5km) are investigated from June to October between 1990 and 1999. Comparisons with the results of a global 20-km-mesh atmospheric climate model (AGCM20km), which provides the boundary conditions for NHM5km, show that NHM5km can improve the reproducibility of precipitation characteristics, including the frequencies of intense precipitation and wet days, from those in AGCM20km. Compared with observations, AGCM20km shows $-30 \%$ and $+33 \%$ biases in terms of the 10 -year mean values of regional maximum precipitation and wet days, respectively, in the region $31^{\circ} \mathrm{N}-38^{\circ} \mathrm{N}$ and $129.8^{\circ} \mathrm{E}-142.0^{\circ} \mathrm{E}$ over Japan from June to October; these biases are reduced to $+9 \%$ and $+12 \%$ in the case of NHM $5 \mathrm{~km}$. The largest biases in AGCM $20 \mathrm{~km}$, overestimation of wet days in July and August, are successfully reduced in NHM5km. Probability density distributions of daily precipitation amount are superior in NHM5km than in AGCM20km for all analysis months, being in strong agreement with a raingaugebased daily precipitation dataset for June-August. These features indicate that NHM5km also provides improved seasonal variations in precipitation characteristics, which are crucial for reliable climate change experiments.
\end{abstract}

\section{Introduction}

An increasing trend in the appearance frequency of intense precipitation has been projected in the future warming climate by many climate change experiments using various global models (e.g., IPCC 2007). Future changes in extreme precipitation are one of the greatest concerns for people in East Asia, where heavy precipitation events $\left(>100 \mathrm{~mm} \mathrm{day}^{-1}\right)$ are often observed.

Even a super-fine global $20-\mathrm{km}$-mesh atmospheric climate model (AGCM20km) underestimates intense precipitation over Japan, although temperature extremes are well represented (Mizuta et al. 2005). On the other hand, Wakazuki et al. (2008) showed a finer-mesh model with a horizontal resolution of $5 \mathrm{~km}$ can reproduce intense precipitation during the Baiu season (June and July) by using the results of regional climate experiments of the Kyousei Project (Yoshizaki et al. 2005), which was the forerunner of the Kakushin Program (Kitoh et al. 2009). In addition, Sasaki et al. (2008) reported that a non-hydrostatic model with a horizontal resolution of $4 \mathrm{~km}$ performed well in reproducing the appearance frequency of intense precipitation. However, these previous studies were subjected to limitations, as the former was carried out only for June and July, and the latter involved 5-year integrations over a limited domain $(400 \times 400 \mathrm{~km})$ covering a small part of Japan.

Corresponding author: Sachie Kanada, Meteorological Research Institute, 1-1, Nagamine, Tsukuba 305-0052, Japan. E-mail: skanada@jamstec.go.jp. (C)2010, the Meteorological Society of Japan.
As part of the Kakushin Program, regional climate change experiments were performed using a non-hydrostatic model with a horizontal resolution of $5 \mathrm{~km}$ (NHM5km), in order to project future changes in precipitation extremes during the main rain season over Japan. By applying the spectral boundary coupling (SBC) method (Yasunaga et al. 2005), the main features of synoptic circulations are inherited from the outer model, AGCM20km. The high performance of NHM5km in producing precipitation extremes has been studied in part using preliminary experiments nested within the Japan Meteorological Agency (JMA) operational regional analysis data with a horizontal resolution of $20 \mathrm{~km}$ for a 5 -year period (Kanada et al. 2008). However, the performance of NHM5km nested in AGCM20km between June and October has yet to be examined.

The purpose of this study is to clarify the performance in the climatological characteristics of precipitation over Japan by NHM5km from June to October for 10 years (1990-1999), compared with the outer model, AGCM20km. The characteristics of daily precipitation are mainly discussed, since it applied in most extreme indices on precipitation (IPCC 2007; Frich et al. 2002)

\section{Model and method}

From 17 May to 31 October for 10-year periods in the present (1990-1999) and future (2086-2095) climates, a non-hydrostatic model with a horizontal resolution of $5 \mathrm{~km}(\mathrm{NHM} 5 \mathrm{~km})$, a climatemodel version of the operational numerical weather-prediction model (JMANHM; Saito et al. 2007), is nested within the 6-hourly results of global warming experiments using AGCM20km under the Special Report on Emission Scenarios A1B scenario (Kitoh et al. 2009; Kanada et al. 2010). This paper focuses on the results of the present climate experiment (1990-1999) in order to clarify the improvement in the climatological characteristics of daily precipitation over Japan obtained from NHM5km compared with AGCM20km.

The domain of NHM5km consists of $669 \times 527$ horizontal grid points, covering a wide region from the East China Sea to the Japanese Islands, and includes 50 stretched vertical layers. The depth of the lowest layer and top height are $40 \mathrm{~m}$ and about $22 \mathrm{~km}$, respectively. The SBC method is employed above a 7-km level. The Kain-Fritsch cumulus parameterization scheme and an improved Mellor-Yamada Level 3 planetary boundary layer scheme are applied (Kanada et al. 2008). The designs of the AGCM20km and NHM5km experiments are described in detail by Kitoh et al. (2009) and Kanada et al. (2008), respectively.

A raingauge-based daily precipitation dataset, Asian Precipitation-Highly Resolved Observational Data Integration Towards the Evaluation of Water Resources (APHRODITE; Kamiguchi et al. 2010), is adopted for verifying the model data. Here, the results of NHM $5 \mathrm{~km}$ and the special version of APHRODITE in the Japan region, which has a horizontal resolution of $0.05^{\circ}$, are averaged over the AGCM $20 \mathrm{~km}$ grid to enable comparisons among the three datasets. 


\section{Results}

\subsection{General characteristics of precipitation}

First, the general characteristics of precipitation over the Japanese Islands are compared among APHRODITE, AGCM20km, and NHM5km. Figure 1 shows the horizontal distributions of 10 -year mean precipitation amount, the number of wet days (daily precipitation amount $>1 \mathrm{~mm}^{-d_{a y}}{ }^{-1}$ ), and the Simple Daily Intensity Index (SDII: Total precipitation amount/wet days; Frich et al. 2002) from June to October between 1990 and 1999 in APHRODITE, AGCM $20 \mathrm{~km}$ and NHM5km. In terms of 10 -year mean precipitation amount from June to October, regions with a large amount $\left(>1500 \mathrm{~mm} \mathrm{season}^{-1}\right)$ are located on the Pacific side of the Japanese Islands, west of $142^{\circ} \mathrm{E}$ in APHRODITE, whereas no such regions are found in AGCM20km. Because NHM5km with the SBC method inherits synoptic circulations from AGCM20km, the horizontal pattern of mean precipitation amount is roughly consistent with that of AGCM20km. However, in NHM5km, regions with values above $1500 \mathrm{~mm}^{-1}$ season $^{-1}$ appear on the Pacific side of the Japanese Islands, as in APHRODITE.

The mean number of wet days in AGCM $20 \mathrm{~km}$ is significantly larger than that in APHRODITE throughout the Japanese Islands. NHM $5 \mathrm{~km}$ also overestimates the mean numbers of wet days, however to a lesser degree than does AGCM20km. Smaller mean precipitation amounts and overestimation of the number of wet days in AGCM $20 \mathrm{~km}$ result a marked underestimation of SDII. According to APHRODITE, SDII values over most of the Japanese Islands reach $15 \mathrm{~mm}_{\text {day }}^{-1}$ in regions west of $141^{\circ} \mathrm{E}$ and south of $37^{\circ} \mathrm{N}$ and exceed $20 \mathrm{~mm}^{\circ}$ day $^{-1}$ in regions west of $137^{\circ} \mathrm{E}$ and south of $36^{\circ} \mathrm{N}$ on the Pacific side of the Japanese Islands. Values in AGCM20km are less than $15 \mathrm{~mm}^{\text {day }}{ }^{-1}$ in most regions, even in the Kyushu area, where large values above $25 \mathrm{~mm}^{\text {day }}{ }^{-1}$ are found in APHRODITE. SDII values in NHM5 $\mathrm{km}$ are smaller than those in APHRODITE, although large SDII values $(>20 \mathrm{~mm}$ day $^{-1}$ ) are reproduced on the Pacific side of the Japanese Islands. Hereafter, a statistical analysis is performed for an area over the Japanese Islands west of $142^{\circ} \mathrm{E}$ and south of $38^{\circ} \mathrm{N}$ (dashed red rectangle in Fig. 1a), which contains most of the areas with mean precipitation amount exceeding $1500 \mathrm{~mm}$ season $^{-1}$ and SDII values above $15 \mathrm{~mm}$ day $^{-1}$.

The above features are statistically summarized in Table 1 . The Regional Maximum Daily Precipitation amounts (R-MDP), defined by the maximum daily precipitation amounts in the dashed red rectangle in Fig. 1a, is adopted as an index of intense precipitation (Kanada et al. 2008). Also estimated are the domainaveraged 10-year mean precipitation amount, number of wet days and SDII (Table 1). A slight underestimation is seen in 10-year mean precipitation amounts in AGCM20km (-7\%) compared with APHRODITE, while the result of NHM5 $\mathrm{km}$ is in good agreement with APHRODITE $(-1 \%)$. R-MDP [wet days, SDII values] in AGCM $20 \mathrm{~km}$ has a $-30 \%[+33 \%,-30 \%]$ bias compared with APHRODITE; for NHM $5 \mathrm{~km}$, the bias is improved to $+9 \%[+12 \%$, $-12 \%]$.

\subsection{Monthly characteristics of precipitation}

The reproducibility of seasonal variations in precipitation characteristics is important in ensuring reliable experiments on future climate change. As mentioned in the previous section, the main features of synoptic circulations (e.g., the locations of highs and disturbances) in NHM5km are inherited from those in the outer model, AGCM $20 \mathrm{~km}$. In this context, monthly changes in precipitation characteristics are statistically compared between AGCM $20 \mathrm{~km}$ and NHM $5 \mathrm{~km}$.

Figure 2 shows monthly variations in R-MDP, domainaveraged monthly precipitation amount, number of wet days, and SDII for the area indicated by the dashed red rectangle in Fig. 1a for a 10 -year period, as produced by APHRODITE (green circles), AGCM20km (blue circles), and NHM5km (red circles). R-MDP is strongly underestimated by AGCM $20 \mathrm{~km}$ and is moderately overestimated by NHM5km (Fig. 2a). Almost all of the R-MDP values in AGCM20km are below $400 \mathrm{~mm} \mathrm{day}^{-1}$, whereas large
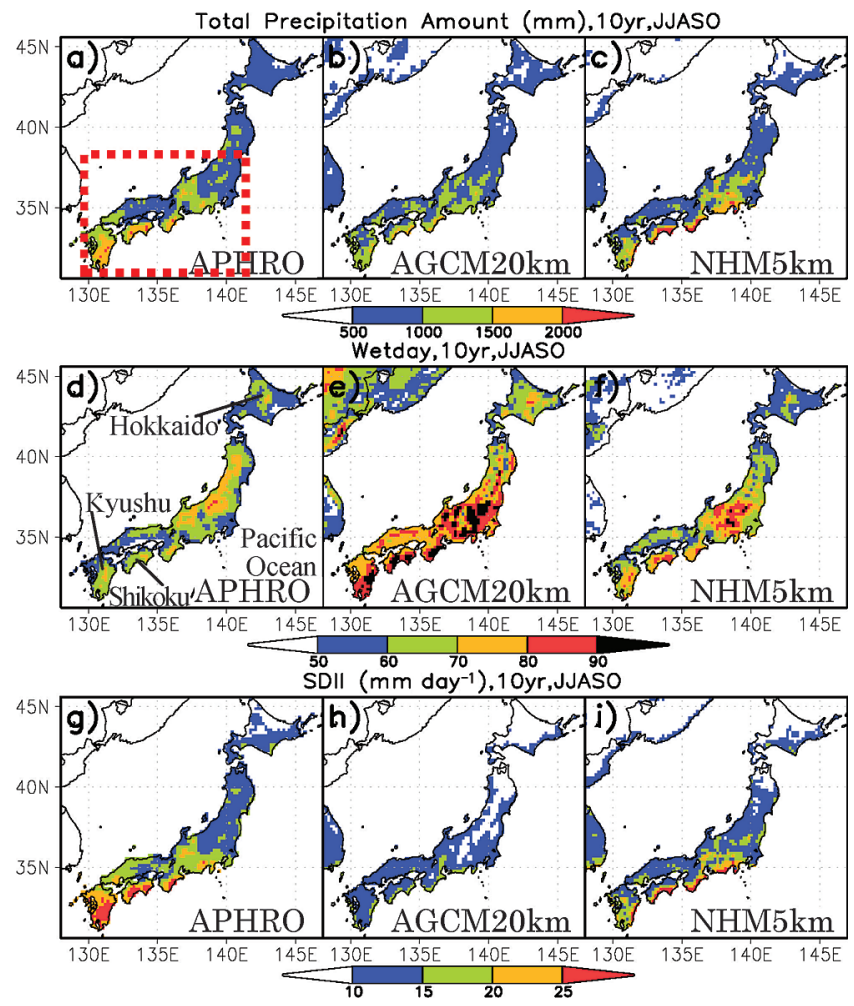

Fig. 1. Horizontal distributions of 10-year mean precipitation amount from June to October $\left(\mathrm{mm} \mathrm{season}^{-1}\right)$ by a) APHRODITE, b) AGCM20km and c) NHM5km between 1990 and 1999. d), e) and f), same as a), b), and c) but for numbers of wet days (day season ${ }^{-1}$ ). g), h) and i), same as a), b) and c) but for SDII (mm day ${ }^{-1}$ ). Data of APHRODITE and NHM5km are averaged over the AGCM $20 \mathrm{~km}$ grid. A dashed red rectangle indicates the analysis region for Table 1 and Figs. 2, 3 and 4.

Table 1. 10-year means of precipitation amount, R-MDP, number of wet days and SDII per year from June to October by APHRODITE, AGCM20km and NHM5km between 1990 and 1999. The values are averaged over the Japanese Islands west of $142^{\circ} \mathrm{E}$ and south of $38^{\circ} \mathrm{N}$ (dashed red rectangle in Fig. 1a).

\begin{tabular}{lcccc}
\hline & & APHRODITE & AGCM20km & \multicolumn{1}{c}{ NHM5km } \\
\hline Precipitation amount & 217.4 & $201.3(-7 \%)$ & $214.9(-1 \%)$ \\
& $\left(\mathrm{mm} \mathrm{mo}^{-1}\right)$ & & & \\
R-MDP & $\left(\mathrm{mm} \mathrm{day}^{-1}\right)$ & 428.4 & $298.7(-30 \%)$ & $465.4(+9 \%)$ \\
Wet days & $\left(\right.$ day mo $\left.^{-1}\right)$ & 12.3 & $16.4(+33 \%)$ & $13.8(+12 \%)$ \\
SDII & $\left(\mathrm{mm} \mathrm{day}^{-1}\right)$ & 17.7 & $12.3(-30 \%)$ & $15.6(-12 \%)$ \\
\hline
\end{tabular}

values, exceeding $500 \mathrm{~mm} \mathrm{day}^{-1}$, are found in APHRODITE for July and September. In NHM5km, such large R-MDP values appear between July and September as in APHRODITE.

The mean monthly precipitation amounts (Fig. 2b) produced by NHM $5 \mathrm{~km}$ and AGCM $20 \mathrm{~km}$ are similar to APHRODITE data, indicating the high performance of reproducibility of the models, although NHM5km and AGCM20km show a slight overestimation [underestimation] for July [September].

The number of wet days in AGCM20km is strongly overestimated compared with APHRODITE data, especially in July and August. The mean number of domain-averaged wet days in AGCM20km is 21.9 and 19.3 days month ${ }^{-1}$ in July and August, respectively, being approximately $60 \%$ more than the number of days in APHRODITE. On the other hands, in NHM5km, this overestimate is reduced to less than $30 \%$.

As a consequence of the consistency of mean precipitation 
amounts and the overestimation of wet days, AGCM20km underestimates SDII values, especially between July-September (Fig. 2d). According to APHRODITE, large mean SDII values appear in July $\left(19 \mathrm{~mm} \mathrm{day}^{-1}\right)$ and September $\left(20 \mathrm{~mm}\right.$ day $\left.^{-1}\right)$, whereas the values in AGCM20 km peak at $14 \mathrm{~mm}$ day-1 in June. The mean SDII values in NHM5km are similar to those in APHRODITE, except in September. These results indicate that NHM5km nested within AGCM20km results in improved precipitation characteristics, including seasonal variations.

Significances of differences of AGCM20km and NHM5km in the each 10-year mean value for each month against APHRODITE are tested by the t-test and high confidence levels above $99 \%$ are assessed especially in wet days for July and August, and in SDII between July and September in AGCM20km.

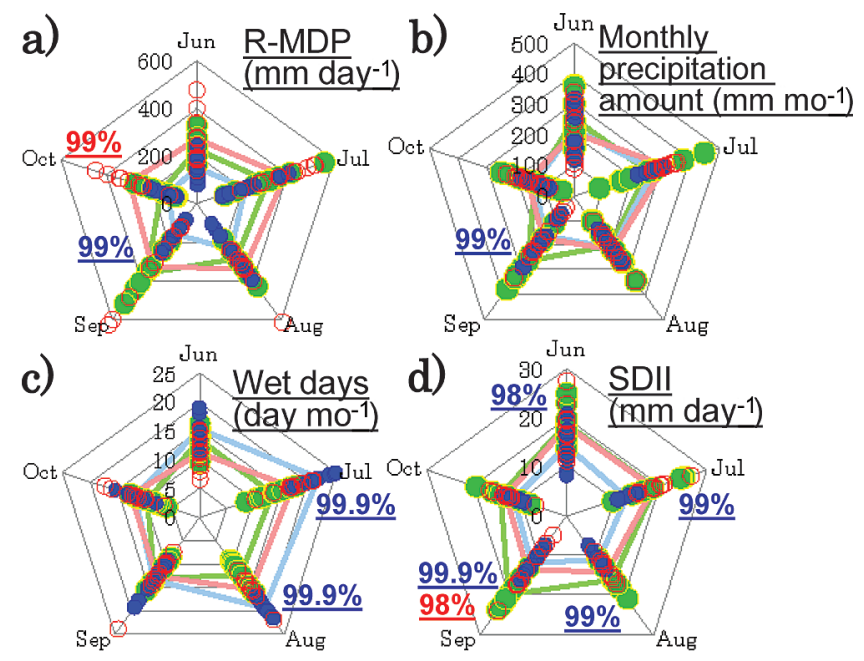

Fig. 2. Monthly variations of a) R-MDP, domain-averaged b) monthly precipitation amount, c) number of wet days and d) SDII in the dashed red rectangle in Fig. 1a for a 10-year period, as produced by APHRODITE (green circles), AGCM20km (blue circles), and NHM5km (open red circles). Each axis for each month shows 10 circles for each product, corresponding to the value for each year in the analysis period. Three thick solid lines represent the 10 -year mean values for each month and dataset. Statistical confidence above the 98\% confidence level based on the Welch's t-test against APHRODITE in the each mean value for each month are attaches with blue (AGCM20km) and red (NHM5km) characters.

Figure 3 compares the three data sets in terms of the monthly probability density distributions (PDD) of daily precipitation amount above $1 \mathrm{~mm}^{\mathrm{may}}{ }^{-1}$ for each $5 \mathrm{~mm}$ bin. Figure 3 a shows the PDD throughout the analysis period, from June to October.

For all months, the AGCM $20 \mathrm{~km}$ model overestimates the frequency of relatively weak precipitation $\left(<26 \mathrm{~mm} \mathrm{day}^{-1}\right)$ and underestimates the frequency of relatively intense precipitation $\left(>26 \mathrm{~mm} \mathrm{day}^{-1}\right)$. These features are consistent with the overestimation of the number of wet days and the underestimation of the intensity of precipitation, as shown in Fig. 2. In contrast, NHM5km successfully reproduces the appearance frequency of daily precipitation amounts smaller than $200 \mathrm{~mm}_{\text {day }}{ }^{-1}$. The PDDs in NHM5km are superior to those in AGCM20km for all months (June-October), showing especially good agreement with those in APHRODITE for June-August.

\subsection{Three largest daily precipitation amounts}

The results presented in previous subsections indicate that the monthly precipitation amounts in AGCM $20 \mathrm{~km}$ are earned by the high appearance frequency of wet days. SDII values are strongly underestimated between July and September, when heavy rainfall often occurs over Japan. Further analyses focused on the reproducibility of precipitation extremes.

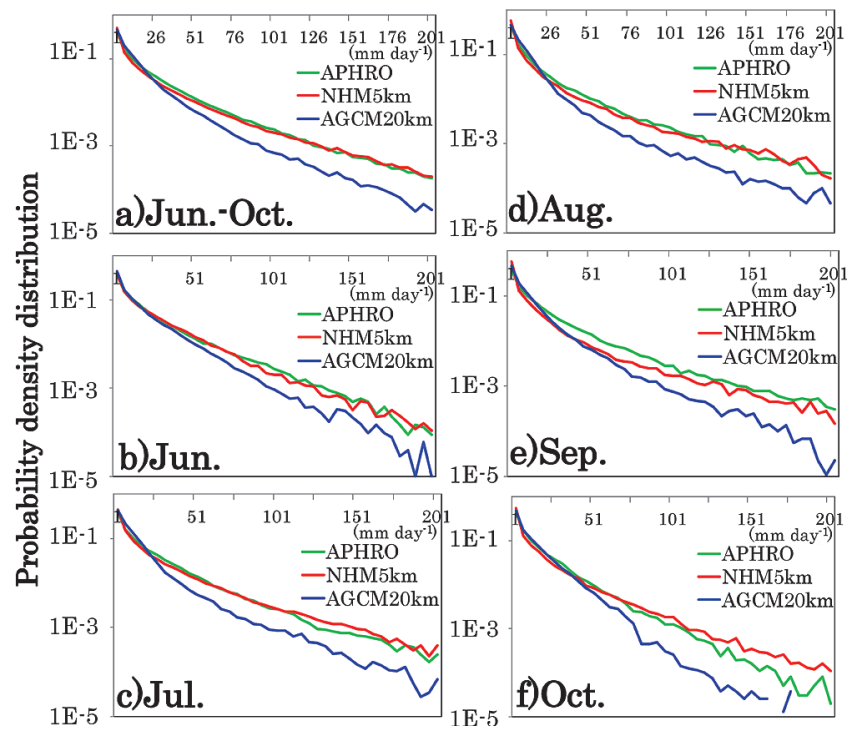

Fig. 3. PDDs of daily precipitation amounts in the dashed red rectangle in Fig. 1a a) from June to October, b) in June, c) in July, d) in August, e) in September and $\mathrm{f}$ ) in October above $1 \mathrm{~mm} \mathrm{day}^{-1}$ for each $5 \mathrm{~mm}$ bins for 10-years period by APHRODITE (green lines), AGCM20km (blue lines) and NHM5km (red lines).

Figure 4 shows the horizontal distribution of the mean topthree daily precipitation amounts in APHRODITE, AGCM20km, and NHM5km, which are averaged from the three largest daily precipitation amounts among the grids of AGCM $20 \mathrm{~km}$ from June to October for a 10-year period (1990-1999). A similar index (PTOP3) is proposed by Wakazuki et al. (2008). In APHRODITE, regions with daily precipitation amounts above $200 \mathrm{~mm}$ day $^{-1}$ are located on the Pacific side of the Japanese Islands south of $37^{\circ} \mathrm{N}$, and regions exceeding $300 \mathrm{~mm}$ day $^{-1}$ are found south of $35^{\circ} \mathrm{N}$. In AGCM $20 \mathrm{~km}$, the mean top-three daily precipitation amounts are relatively small, with most regions north of $35^{\circ} \mathrm{N}$ receiving less than $100 \mathrm{~mm}^{-1}$ day $^{-1}$. Regions with amounts exceeding $200 \mathrm{~mm}$ day $^{-1}$ are only detected in the limited regions on the Pacific side of Kyushu and Shikoku Islands. The horizontal pattern of the mean top-three daily precipitation amounts in NHM5km is largely consistent with that in APHRODITE. Regions exceeding $100 \mathrm{~mm} \mathrm{day}^{-1}$ in NHM5km cover most of the Japanese Islands, except Hokkaido, and regions exceeding $200 \mathrm{~mm}^{-1}{ }^{-1}$ are located on the Pacific side of the Japanese Islands, although values are overestimated in western Kanto, and Kyushu and Shikoku Islands. The PDDs of the three largest daily precipitation amounts from June to October for a 10-year period (for the area indicated by the dashed rectangle in Fig. 1a) are in good agreement between NHM5km and APHRODITE, whereas a leftward shift of the peak is seen in AGCM20km (Fig. 4d).

\section{Summary and future work}

To project future changes in precipitation extremes during the warm season over the Japanese Islands, regional climate experiments were conducted using a non-hydrostatic model with a horizontal resolution of $5 \mathrm{~km}$ (NHM5km) for 10 -year periods in the present (1990-1999) and future (2086-2095) climates, with the boundary conditions based on the results of global warming experiments by a global $20-\mathrm{km}$ atmospheric model (AGCM20km). To assess the performance of NHM5km, the climatological characteristics of daily precipitation in NHM5km in the present climate experiment were compared with those in AGCM $20 \mathrm{~km}$ over the Japanese Islands.

The results reveal that the NHM5km provides more realistic precipitation characteristics than those in the outer model, 


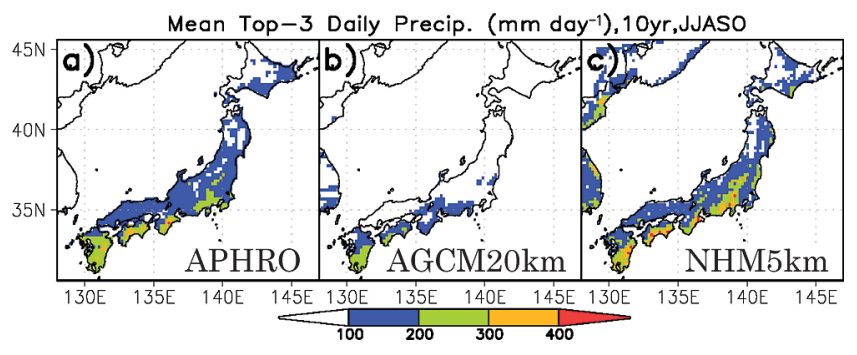

\section{References}

Frich, P., L. V. Alexander, P. Della-Manta, B. Gleason, M. Haylock, A. M. G. Klein Tank, and T. Peterson, 2002: Observed coherent changes in climate extremes during the second half of the twentieth century. Clim. Res., 19, 193-212.

IPCC, 2007: Climate Change 2007: The Physical Science Basis. Contribution of Working Group I to the Forth Assessment Report of the Intergovernmental Panel on Climate Change, S. Solomon, D. Qin, M. Manning, Z. Chen, M. Marquis, K. B. Averyt, M. Tignor, and H. L. Miller, Eds., Cambridge University Press, Cambridge, United Kingdom and New York, NY, USA, 996 pp.

Kamiguchi, K., O. Arakawa, A. Kitoh, A. Yatagai, A. Hamada, and N. Yasutomi, 2010: Development of APHRO_JP, the first Japanese high-resolution daily precipitation product for more than 100 years. Hydro. Res. Lett., 4, 60-64.

Kanada, S., M. Nakano, A. Hayashi, T. Kato, M. Nakamura, K. Kurihara, and A. Kitoh, 2008: Reproducibility of maximum daily precipitation amount over Japan by a high-resolution non-hydrostatic model. SOLA, 4, 105-108.

Fig. 4. Horizontal distributions of the mean top-3 daily precipitation amounts in a) APHRODITE, b) AGCM20km and c) NHM5km. The three largest daily precipitation amounts from June to October for 10-year period are averaged over the AGCM20km grid. d) Same as Fig. 3 but for the three largest precipitation amounts for a 10 -year period.

AGCM20km. Probability density distributions of daily precipitation amounts in NHM5km in the region $31^{\circ} \mathrm{N}-38^{\circ} \mathrm{N}$ and $129.8^{\circ} \mathrm{E}-142.0^{\circ} \mathrm{E}$ over the Japanese Islands are superior to those in AGCM20km for all analysis months (June-October), being in good agreement with a raingauge-based daily precipitation dataset (APHRODITE) for June-August. The 10-year mean regional maximum precipitation (R-MDP) and number of wet days from June to October in AGCM20km have biases of $-30 \%$ and $+33 \%$, respectively, compared with APHRODITE. These biases are reduced to $+9 \%$ and $+12 \%$ in NHM $5 \mathrm{~km}$, respectively.

The number of wet days is overestimated in AGCM $20 \mathrm{~km}$, especially in July $(+61 \%)$ and August $(+56 \%)$, and intense precipitation is underestimated. The reproducibility of seasonal variations in precipitation characteristics is required for more reliable projections in climate change experiments. In this context, the results obtained from NHM5km are superior to those obtained from AGCM20km, as the seasonal variations in R-MDP and SDII, as produced by NHM $5 \mathrm{~km}$, are more similar to those in APHRODITE.

A number of uncertainties are expected to influence the reliability of future climate-change projections. As part of the Kakushin Program, several members of ensemble experiments have been conducted using AGCMs. To reduce any uncertainties, downscaling experiments are planned, using NHM5km nested in these results. The 25 -year periods experiments from 17 May to 31 October have been also executing by both NHM5km and NHM $2 \mathrm{~km}$, a NHM with a horizontal resolution of $2 \mathrm{~km}$.

\section{Acknowledgments}

This study was supported by the Ministry of Education, Culture, Sports, Science and Technology of Japan under the framework of the Kakushin Program. Numerical simulations were performed using the Earth Simulator. The Kakushin-3 modeling group is gratefully acknowledged for carrying out the project. The authors are grateful to Dr. M. Nakamura, Mr. S. Hayashi, and Mr. $\mathrm{H}$. Tsuguti for valuable discussions.

Kanada, S., M. Nakano, and T. Kato, 2010: Changes in mean atmospheric structures around Japan during July due to global warming in regional climate experiments using a cloudsystem resolving model. Hydro. Res. Lett., 4, 11-14.

Kitoh, A., T. Ose, K. Kurihara, S. Kusunoki, M. Sugi, and KAKUSHIN Team-3 Modeling Group, 2009: Projection of changes in future weather extremes using super-highresolution global and regional atmospheric models in the KAKUSHIN Program: Results of preliminary experiments. Hydro. Res. Lett., 3, 49-53.

Mizuta, R., T. Uchiyama, K. Kamiguchi, A. Kitoh, and A. Noda, 2005: Changes in extremes indices over Japan due to global warming projected by a global $20-\mathrm{km}$-mesh atmospheric model. SOLA, 1, 153-156.

Saito, K., J. Ishida, K. Aranami, T. Hara, T. Segawa, M. Narita, and Y. Honda, 2007: Nonhydrostatic atmospheric models and operational development at JMA. J. Meteor. Soc. Japan, 85B, 271-304.

Sasaki, H., K. Kurihara, I. Takayabu, and T. Uchiyama, 2008: Preliminary experiments of reproducing the present climate using the non-hydrostatic regional climate model. SOLA, 4 , 25-28.

Wakazuki, Y., M. Nakamura, S. Kanada, and C. Muroi, 2008: Climatological reproducibility evaluation and future climate projection of extreme precipitation events in the Baiu Season using high-resolution non-hydrostatic RCM in comparison with an AGCM. J. Meteor. Soc. Japan, 86, 951-967.

Yasunaga, K., H. Sasaki, Y. Wakazuki, T. Kato, C. Muroi, A. Hashimoto, S. Kanada, K. Kurihara, M. Yoshizaki, and Y. Sato, 2005: Performance of the long-term integrations of the Japan Meteorological Agency nonhydrostatic model with use of the spectral boundary coupling method. Wea. Forecasting, 20, 1061-1072.

Yoshizaki, M., C. Muroi, S. Kanada, Y. Wakazuki, K. Yasunaga, A. Hashimoto, T. Kato, K. Kurihara, A. Noda, and S. Kusunoki, 2005: Changes of Baiu (Mei-yu) frontal activity in the global warming climate simulated by a non-hydrostatic regional model. SOLA, 1, 25-28.

Manuscript received 11 June 2010, accepted 30 August 2010 SOLA: http://www.jstage.jst.go.jp/browse/sola/ 